\title{
Annexin V-binding and assisted reproduction technologies
}

\author{
Flavia Denaday
}

Reproductive Medicine Clinic, Buenos Aires, Argentina

Email: denadayflavia@gmail.com

Received 13 June 2013; revised 13 July 2013; accepted 20 July 2013

Copyright (C) 2013 Flavia Denaday. This is an open access article distributed under the Creative Commons Attribution License, which permits unrestricted use, distribution, and reproduction in any medium, provided the original work is properly cited.

\begin{abstract}
The objective is to describe the impact annexin $\mathrm{V}$ binding technique has on couples diagnosed with male infertility and how to optimize sperm parameters so that this technique contributes to simplify the assisted reproductive treatment that will be prescribed [1-4]. Empirical studies and expert consensus related to the physiological and medical aspects of the use of annexin V-binding which were presented in this study were identified in articles through bibliographical research.
\end{abstract}

Keywords: Annexin V-Binding; DNA Fragmentation; TUNEL; IUI

\section{INTRODUCTION}

The apoptosis or programmed cell death consists of various cellular mechanisms before the end of the process occurs. Apoptotic markers used at present in human spermatozoa include the analysis of phosphatidylserine externalization's levels or early apoptosis and in the case of late apoptosis, they include active caspase-3 and DNA fragmentation [5].

The DNA damage may be simple and/or double-strand breaks and it has been assessed by different methods, among which the TUNEL (Terminal deoxynucleotidyl transferase-mediated dUTP nick-end labeling) technique stands out [6].

\section{ANALYSIS OF SPERMATOZOA}

\subsection{Risk Factors and Techniques}

The above mentioned damage may occur during the stage of spermatogenesis or during the spermatozoa's transit through the epididymis and it may be induced by physical factors as well as metabolic ones. Risk factors associated with the increase in DNA fragmentation have been identified. For example: some lifestyle habits such as the exposure to toxic substances, marijuana or tobacco smoking [1,7-9]. Other factors to be mentioned include the presence of a high fever, high testicular temperature, environmental contamination, varicocele, hormonal factors or an advanced patient age. Moreover, there could also be mentioned cryptorchidism, radiation therapy and chemotherapy. It is important to remark that the molecular mechanism involved in these pathologies is still under intensive research. Numerous publications report that the sperm quality with annexin V-binding or its acronym in English: MACS (Magnetic Activated Cell Sorting), when it is performed after the density gradient centrifugation, results in the separation of a sperm population of the highest quality especially evidenced in its mobility and viability levels as well as in a decreased presence of apoptotic markers [10].

The results achieved were significantly different compared to the values detected in the sperm selected only by density gradient centrifugation (standard sperm preparation technique), which means that these cases may benefit from the mentioned additional techniques [11].

\subsection{Apoptosis}

Through this, it was clearly identified a correlation between the presence of apoptotic markers, such as the caspase activation, the mitochondrial membrane potential, the externalization of phosphatidylserine and the sperm quality in terms of viability and motility values, among others [5].

Some studies suggest that the apoptosis controls the super production of male gametes in masculine reproduction. Studies performed in animals have even described apoptosis as a key spermatogenesis regulator in normal and pathological samples [12].

Another number of studies have documented the implication of the apoptosis deregulation in the male infertility pathogenesis [12]. 
As we know, every sperm sample containing spermatozoa presents apoptotic spermatozoa in a normal proportion; when the percentage of apoptotic spermatozoa is higher than normal we recommend annexin V-binding.

\section{ANNEXIN V-BINDING}

There are extensive publications which support the benefits of the results obtained with this technique, when used prior to ICSI (Intracytoplasmic Sperm Injection), highlighting the probability that some selected spermatozoa for the assisted reproduction may exhibit features of apoptosis regardless its normal appearance. This scenario reduces the fertilization potential, the embryo quality, the embryo development to the blastocyst stage, and the implantation and pregnancy rates as well as it increases spontaneous miscarriage rates $[11,13]$. Therefore, annexin V-binding technique may be indicated prior to ICSI, in order to guarantee that the injected spermatozoa are not damaged at a molecular level $[14,15]$. Nevertheless, other authors describe the sperm DNA's damage as a useful factor to be identified in the assessment of IUI (Intrauterine Insemination) success rates, stating that it is not a factor with a negative impact on ICSI treatments. So, they assert that the human sperm DNA has a significant value in estimating the chances of achieving a clinic pregnancy after an IUI, but they confirm that DNA fragmentation does not seem to influence in the chances of achieving a successful result after an ICSI [3].

Fertility may be clearly compromised by male factors which may medically benefit from the use of oral antioxidants and at the time of the fertilization assisted treatment they may be improved by the annexin V-binding technique. In order to do that, samples must fulfill some requirements: specific sperm parameters should be present in such a way that when the sperm sample is treated in its first fraction, that is to say after the gradient, the positive fraction (called like this due to the fact that the spermatozoa stay retained in the magnetic columns because of their damaged DNA) will allow us to recover a negative fraction (made up of spermatozoa with unharmed DNA), with optimal sperm characteristics to be able to proceed $[16,17]$. In other words, the spermatozoa passing through the magnetic columns without being retained will prove to have an unharmed DNA and, therefore, they will be eligible to be used. Consequently, specific criteria should be adopted: the initial fraction should not be so severe at the time of indicating a future IUI, that is to say, it must show some sperm parameters which allow us to apply this technique because, if the sample reveals borderline parameters, we run the risk of collecting a very small negative fraction [3]. Anyway, the previous treatment with orally administered antioxidants will not be in vain because performing an ICSI treatment with an improved sperm sample will also im- prove the chances of getting pregnant [17].

\section{CONCLUSIONS}

It is frequently observed in everyday consultations that there is an excessive number of high complexity Assisted Fertilization Treatments, IVF (In Vitro Fertilization), especially in patients who cannot achieve pregnancy with IUI when no diagnosis is attained due to some missing information about one of the members of the couple. Although couples subject to an artificial insemination who are treated during three or four menstrual cycles have a pregnancy rate of only $18 \%$ to $20 \%$ after completion of the four cycles, other potential infertility factors may be studied to enhance the results [4].

One of the fundamental pillars is to question the couple about their intercourse timing and frequency and, at the same time, guide them wisely if there is any difficulty in this regard, for example suggesting psychological counseling. The TUNEL or MACS technique consists of a noninvasive, low cost simple procedure and all andrology laboratories, as they are outfitted with the ART scientific equipment and have a team of skilled laboratory professionals who should also provide this technique. In order to avoid the excessive use of the annexin V-binding Technique, the physician in charge of conducting the male's evaluation should be informed of the causes known to that date before recommending this technique [18].

As a clear example of the mentioned causes we could refer to the infections produced by germs which cause infertility and which in most of the cases do not show any other symptom except for infertility problems in the couple. Chlamydia trachomatis, Ureaplasma urealyticum, Mycoplasma and some common germs, among others, can be the cause of sperm DNA fragmentation which should be medically treated before MACS is analyzed and indicated. Once that diagnosis is reached, the couple can be treated with a simple scheme of broadspectrum antibiotics. The couple should be informed of the other causes of sperm DNA fragmentation which are modifiable such as lifestyle habits, among other previously mentioned factors $[4,15]$.

Once the causes of the decrease in the molecularly damaged spermatozoa's percentage have been corrected, the TUNEL diagnosis should be requested in the best judgment of the attending physician.

In conclusion, mastering the professional use of this technique in order to obtain significant enrichment of the sperm prior to the IUI may be a way to avoid excessive implementation of high complexity Assisted Reproductive Technologies (ART), such as IVF or ICSI.

\section{ACKNOWLEDGEMENTS}

The author gratefully acknowledges Mrs. Silvia Bottero for translating 
the text and Lic. María Bernadette Houssay.

\section{REFERENCES}

[1] Huang, H., Hansen, K.R., Factor-Litvak, P., Carson, S.A., Guzick, D.S., Santoro, N., Diamond, M.P., Eisenberg, E., Zhang, H. and the National Institute of Child Health and Human Development Cooperative Reproductive Medicine Network (2012) Predictors of pregnancy and live after insemination in couples with unexplained or malefactor infertility. Fertility and Sterility, 97, 959-967.

[2] Duran, E.H., Morshedi, M., Taylor, S. and Oehninger, S. (2002) Sperm DNA quality predicts intrauterine insemination outcome: A prospective cohort study. Human Reproduction, 17, 3122-3128. http://dx.doi.org/10.1093/humrep/17.12.3122

[3] Thomson, L.K., Zieschang, D.J.A. and Clark, A.M. (2011) Oxidative deoxyribonucleic acid damage in sperm has a negative impact on clinical pregnancy rate in intrauterine insemination but not intracytoplasmic sperm injection cycles. Fertility and Sterility, 96, 843-847. http://dx.doi.org/10.1016/i.fertnstert.2011.07.356

[4] Denaday, F. (2012) Intrauterine Insemination (IUI). Journal Fertilization in Vitro, IVF-Worldwide, Reproductive Medicine, Genetics \& Stem Cell Biology, 1, 116.

[5] de Vantéry Arrighi, C., Lucas, H., Chardonnens, D. and de Agostini, A. (2009) Removal of spermatozoa with externalized phosphatidylserine from sperm preparation in human assisted medical procreation: Effects on viability, motility and mitochondrial membrane potential. Reproductive Biology and Endocrinology, 7, 1. http://dx.doi.org/10.1186/1477-7827-7-1

[6] Hoogendijk, C.F., Henkel, R.R., Kruger, T.F. and Patric, J.D. (2009) A novel approach for the selection of human sperm using annexin V-binding and flow cytometry. Fertility and Sterility, 91, 1285-1292.

http://dx.doi.org/10.1016/j.fertnstert.2008.01.042

[7] Wong, W.Y., Thomas, C.M., Merkus, J.M., Zielhuis, G.A. and Steegers-Theunissen, R.P. (2000) Male factor subfertility: Possible causes and the impact of nutritional factors. Fertility and Sterility, 73, 435-442.

[8] Hassan, M.A.M. and Killick, S.R. (2004) Negative lifestyle is associated with a significant reduction in fecunddity. Fertility and Sterility, 81, 384-392. http://dx.doi.org/10.1016/j.fertnstert.2003.06.027

[9] Iaizzo, P.R., Martinez, A.G., Cattaneo, A.R. and Ruhlmann, C. (2010) Statistical Model to predict the impact of different lifestyle and environmental on seminal parameters. Fertility and Sterility, 94, 230.

[10] Akl, L.D., Oliveira, J.B., Petersen, C.G., Mauri, A.L.,
Silva, L.F., Massaro, F.C., Baruffi, R.L., Cavagna, M., Franco Jr., J.G. and Silva, L.F. (2011) Efficacy of the motile sperm organelle morphology examination (MSOME) in predicting pregnancy after intrauterine insemination. Reproductive Biology and Endocrinology, 9, 120. http://dx.doi.org/10.1186/1477-7827-9-120

[11] Said, T.M., Agarwal, A., Zborowski, M., Grunewald, S., Glander, H.J. and Paasch, U. (2008) Utility of magnetic cell separation as a molecular sperm preparation technique. Journal of Andrology, 29, 134-142.

[12] Glander, H.J. (2005) Advantage of combining magnetic cell separation with sperm preparation techniques. Reproductive BioMedicine Online, 10, 740-746.

[13] Parmegiani, L., Cognigni, G.E., Bernardi, S., Troilo, E., Ciampaglia, W. and Filicori, M. (2010) "Physiologic ICSI": Hyaluronic acid (HA) favors selection of spermatozoa without DNA fragmentation and with normal nucleus, resulting in improvement of embryo quality. Fertility and Sterility, 93, 598-604. http://dx.doi.org/10.1016/j.fertnstert.2009.03.033

[14] Polak de Fried, E. and Denaday, F. (2010) Single and twin ongoing pregnancies in two cases of previous ART failure after ICSI performed with sperm. Fertility and Sterility, 94, 351. http://dx.doi.org/10.1016/j.fertnstert.2009.12.037

[15] Lee, T.H., Liu, C.H., Shih, Y.T. Tsao, H.M., Huang, C.C., Chen, H.H. and Lee, M.S. (2010) Magnetic-activated cell sorting for sperm preparation reduces spermatozoa with apoptotic markers and improves the acrosome reaction in couples with unexplained infertility. Human Reproduction, 25, 839-846. http://dx.doi.org/10.1093/humrep/deq009

[16] Franco Jr., J.G., Mauri, A.L., Petersen, C.G., Massaro, F.C., Silva, L.F.I., Felipe, V., Cavagna, M., Pontes, A., Baruffi, R.L.R., Oliveira, J.B.A. and Vagnini, L.D. (2012) Large nuclear vacuoles are indicative of abnormal chromatin packaging in human spermatozoa. International Journal of Andrology, 35, 46-51. http://dx.doi.org/10.1111/j.1365-2605.2011.01154.x

[17] Abad, C., Amengual, M.J., Gosàlvez, J., Coward, K., Hannaoui, N., Benet, J., Garcia-Peirò, A. and Prats, J. (2012) Effects of oral antioxidant treatment upon the dynamics of human sperm DNA fragmentation and subpopulations of sperm with highly degraded DNA. Andrologia, 45, 211-216.

[18] Said, T.M., Grunewald, S., Paasch, U., Glander, H.J., Baumann, T., Kriegel, C., Li, L. and Agarwal, A. (2005) Advantage of combining magnetic cell separation with sperm preparation techniques. Reproductive BioMedicine, 10, 740-746. 